\title{
Transport of the pituitary adenylate cyclase-activating polypeptide across the blood-brain barrier: implications for migraine
}

\author{
Faisal Mohammad Amin ${ }^{*}$ and Henrik Winther Schytz
}

\begin{abstract}
Background: Pituitary adenylate cyclase-activating polypeptide (PACAP) is widely distributed in the nervous system and is involved in migraine pathophysiology. Understanding the function of the blood-brain barrier (BBB) in relation to PACAP is important to the understand the mechanisms behind PACAP-induced migraine attacks, but also to develop antimigraine drugs targeting the PACAP receptors Here, we aim to review the transport ability of PACAP across the BBB.

Methods: We performed a systematic literature search on PubMed to identify studies reporting original data on PACAP and BBB. The search was finalized in July 2017.

Results: The literature search identified 96 papers of which 11 contained relevant data. In addition, two papers were known to be relevant and were included. A total of 13 papers studies were included in the final analysis. Preclinical studies $(n=10)$ suggest the existence of specific PACAP transport systems across the BBB, while human PACAP studies failed to show vasodilator effect of PACAP on the cerebral arteries from the lumen $(n=3)$.

Conclusion: PACAP38 is transported over the BBB actively, while PACAP27 cross the BBB by diffusion over the membrane, but after crossing the endothelial membrane both isoforms are either rapidly degraded or efflux back from brain to blood. Thus, a direct central action of the PACAPs is unlikely. This is supported by studies showing selective PACAP effect on extra-cerebral arteries.
\end{abstract}

Keywords: Migraine, PACAP, Blood-brain barrier

\section{Review}

The peptide pituitary adenylate cyclase-activating polypeptide (PACAP) is widely distributed in the nervous system and is found in two major isoforms, PACAP38 and PACAP27, which exert various effects via activation of the VPAC1, VPAC2 and PAC1 receptors [1]. A growing body of evidence suggests that PACAP plays an important role in migraine pathogenesis. For example, intravenous infusion of PACAP38 provokes migraine attacks in migraine patients without aura $[2,3]$ and induces a marked sustained dilation of extra-cerebral

\footnotetext{
* Correspondence: faisal@dadlnet.dk

Danish Headache Center, Department of Neurology, Rigshospitalet Glostrup, University of Copenhagen, Valdemar Hansens Vej 1A, 2600 Glostrup, Denmark
}

but not intracerebral arteries in both healthy volunteers [4] and migraine patients [5]. The exact mechanisms of PACAP38 induced migraine are unknown. However, given the abundant distribution of PACAP in the CNS [6], central pain mechanisms caused by exogenous PACAP infusion could hypothetically be important. This raises the important question to which degree PACAP may cross the blood-brain barrier (BBB). Preclinical studies have reported an active transport system of PACAP38 across the BBB in the rat [7]. However, investigations of rat and human cerebral arteries in vitro, showed that PACAP38 only had effect after abluminal but not luminal application [8]. Understanding the function of the BBB in relation to PACAP is important to the understand the mechanisms behind PACAP-induced migraine attacks triggering, but also to 
develop antimigraine drugs targeting the PACAP receptors [9]. Here, we aimed to present a systematic review on studies investigating the transport of PACAP across the BBB.

\section{Methods and materials}

We performed a systematic literature search in July 2017 via PubMed to identify studies reporting original data on PACAP in relation to the BBB. The following search terms were used: pituitary adenylate cyclase activating polypeptide or PACAP and blood brain barrier or BBB. No filters were used in the search. Only studies reporting original data published in Englishwritten peer-reviewed journals were included. The first author assessed all titles and abstracts to identify articles containing relevant data. Subsequently, the entire articles were read and additional studies known to be relevant were also included.

\section{Results}

Our search strategy resulted in 96 hits out of which 11 studies were included in the final review. In addition, two studies known to be relevant by the authors were also included ending up with a total of 13 studies (Tables 1 and 2). Two out of 13 studies exclusively examined human arteries $[4,5]$, while one study reported data on rat and human arteries [8]. The remaining ten studies investigated mice [10-18] or rat models [19]. Only one of the studies were performed as migraine models [5].

\section{Discussion}

The main finding in this review is that PACAP can cross the $\mathrm{BBB}$ in both directions (i.e. from blood to brain and from brain to blood). Preclinical studies carried out in mice or rats consistently report that PACAP38 is transported actively from the blood to the brain (influx) and from the brain to blood (efflux) by the protein transport system-6 (PTS-6), which is located in the endothelium. In contrast, studies investigating effect of PACAP38 on the cerebral arteries (i.e. middle cerebral artery [MCA]) suggest that PACAP38 is not able to cross the endothelium in sufficient amount to activate receptors in the smooth muscle cells in the arterial walls $[4,5,8]$, which will be discussed in the following. Historically, the BBB was considered as a structural barrier between the blood and brain consisting of capillary endothelial cells glued together with tight junctions and surrounded by glial cell projections. We now know that the BBB is a functional rather than just a solid structural barrier, allowing passage in from blood to brain and from brain to blood via different mechanisms. Peptides that cross the BBB are either actively transported by saturable carrier- or receptor- mediated mechanisms or by non-saturable transmembrane or intercellular diffusion. Banks and colleagues [10] first demonstrated that both PACAP27 and PACAP38 could cross the BBB. Interestingly, the permeability for PACAP38 decreased as the concentration of PACAP38 increased in the blood, which was not true for PACAP27. Based on these initial observations authors suggested that PACAP38 traversed the $\mathrm{BBB}$ via a saturable mechanism, whereas the PACAP27 uptake must be via a non-saturable mechanism [10]. Ki (influx constant) for PACAP38 $(2.86 \mu \mathrm{L} / \mathrm{g} / \mathrm{min})$ was slightly higher than and PACAP27 $(2.13 \mu \mathrm{L} / \mathrm{g} / \mathrm{min})$ although PACAP38 is a larger and less lipid soluble molecule. However, the percentage of intact iodine-labelled PACAP27 (I-PACAP27) in the brain was $76.9 \%$ versus 58.9\% for the PACAP38 [10]. Taken together, these observations suggest efflux of PACAP27 from the brain to blood via the saturable beta-F1 ATPase, which is highly specific for PACAP27 [16]. Interestingly, the passage of PACAP38 was not affected by a general disruption of the $\mathrm{BBB}$ by lipopolysaccharide [15], but after occlusion of the MCA [19].

Two human MR-angiography studies found no functional effect of intravenously infused PACAP38 on the MCA but a $17-19 \%$ and $2 \mathrm{~h}$ sustained dilation of the middle meningeal artery (MMA) in healthy volunteers [4] and migraine patients [5]. Interestingly in vitro studies reported presence of PACAP receptors in the meningeal as well as cerebral arteries [20, 21]. Thus, the selective dilation of the MMA but not the MCA may suggest that intravenously administrated PACAP38 most likely did not cross the BBB. Another human study has shown that infusion of PACAP38 can induce premonitory symptoms in $48 \%$ of patients with induced attacks [22], which may be a central effect via the hypothalamus [23]. However, PACAP38 infusion did not induce more premonitory symptoms in patients who developed an attack compared with those who did not develop an attack, which suggest that induction of premonitory symptoms is not a necessary mechanism for the induction of migraine. Moreover, PACAP38induced migraine attacks are accompanied by change in the intrinsic brain connectivity [24]. These observations suggest either that there is a difference between species or that the efflux mechanisms for PACAP38 work even faster in man to transport PACAP38 from the endothelial cells back to the blood. Thus, PACAP cannot exert its effect although it can cross the BBB or enter the endothelial cells. In contrast, Nonaka et al. [14] reported the highest amount of iodine-labelled PACAP38 (I-PACAP38) in for instance the hypothalamus. Alternatively, the PTS-6 system may be limited to the capillary endothelium and not the large arteries of the brain, where the endothelium may work as a structural barrier 


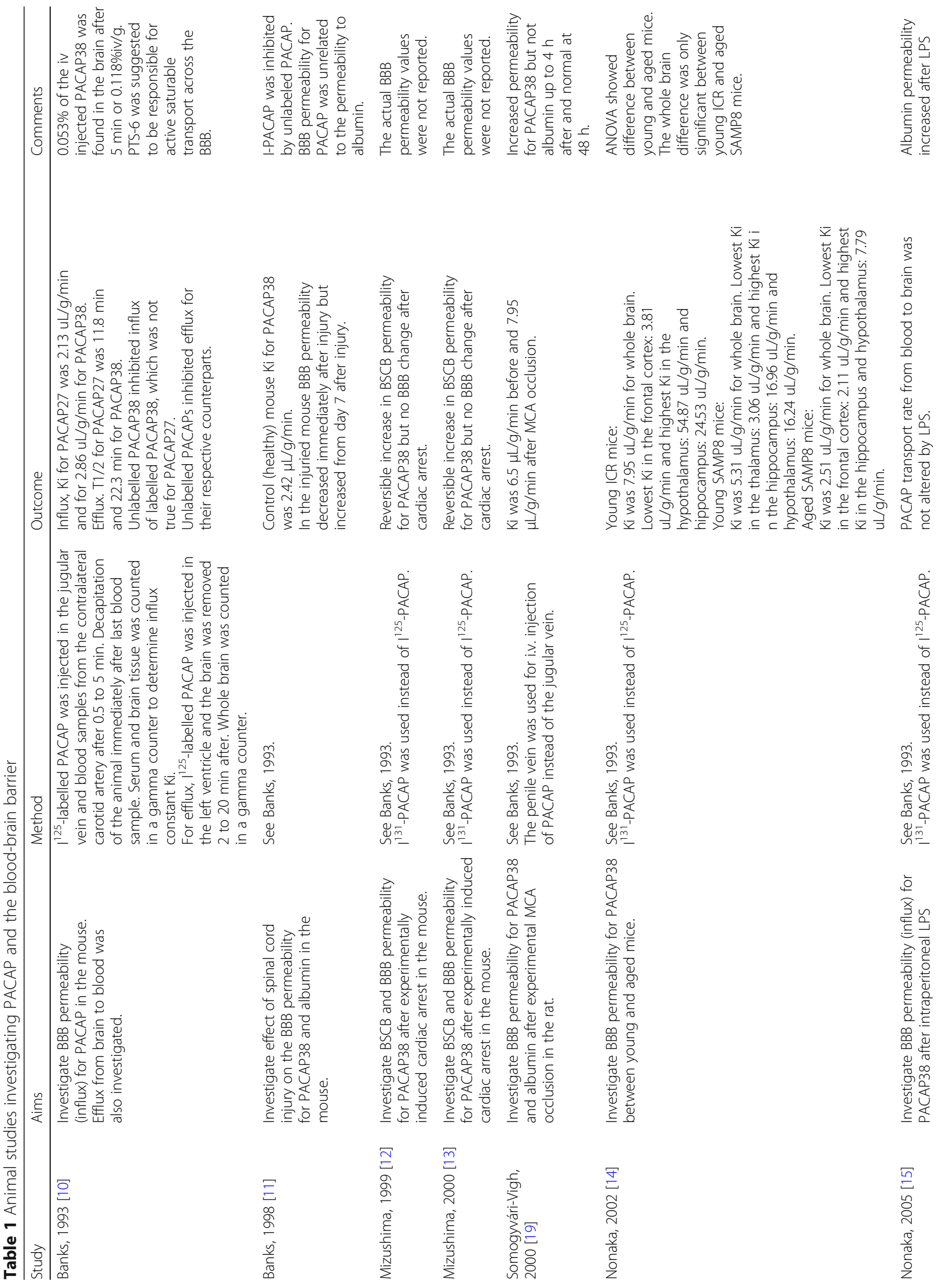




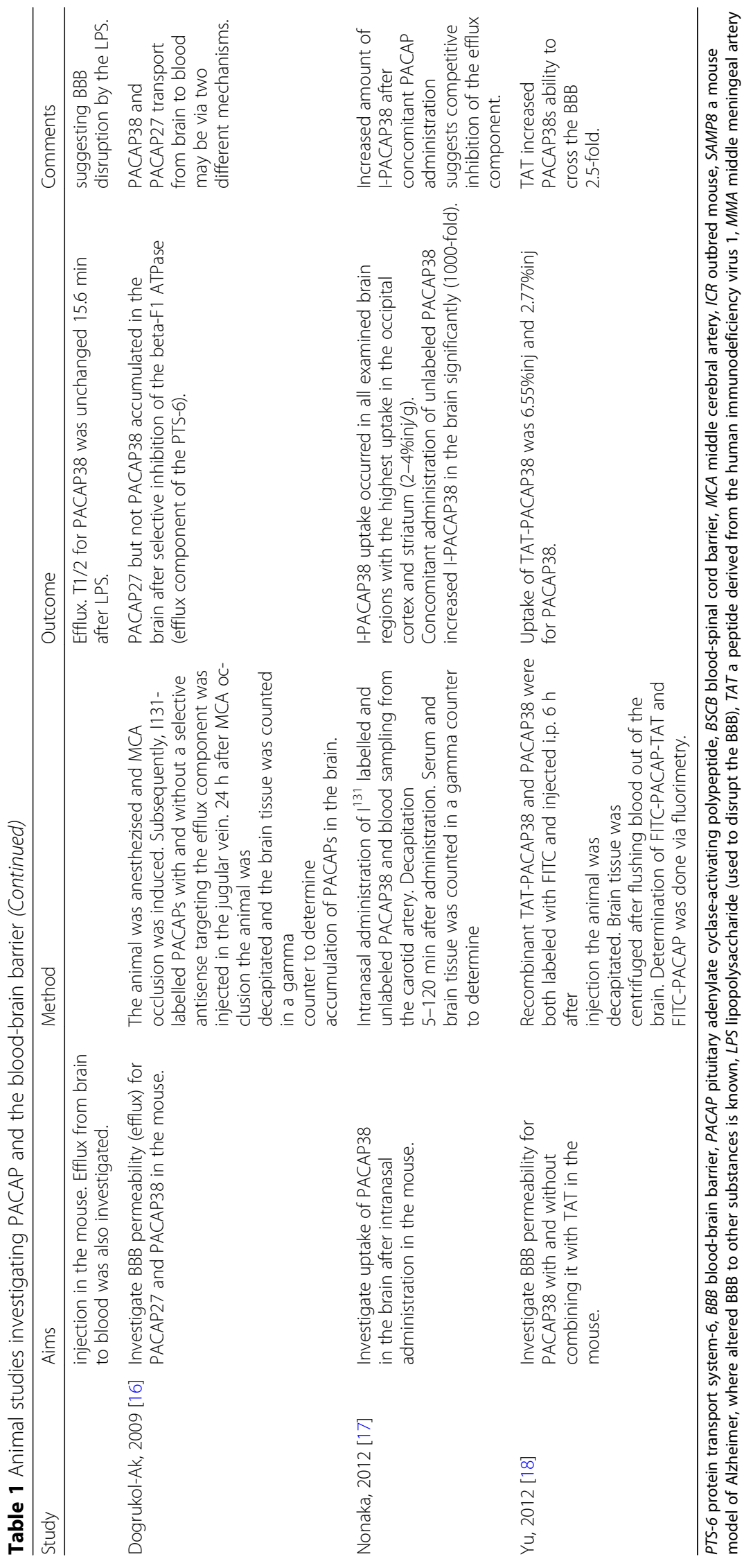


Table 2 Human studies presenting data relevant for understanding PACAP transport across the blood-brain barrier

\begin{tabular}{|c|c|c|c|c|}
\hline Grände, 2013 [8] & $\begin{array}{l}\text { Investigate effect of PACAP27 and } \\
\text { PACAP38 on human and } \\
\text { rat arteries. }\end{array}$ & $\begin{array}{l}\text { In vitro myograph of human } \\
\text { MCA and in vitro pressurized } \\
\text { arteriography of rat MCA. }\end{array}$ & $\begin{array}{l}\text { PACAP38 and PACAP27 had } \\
\text { effect after abluminal but not luminal } \\
\text { application in the rat. Both PACAPs } \\
\text { had effect on the human MCA abluminal. }\end{array}$ & $\begin{array}{l}\text { Luminal application } \\
\text { of PACAP to the } \\
\text { human MCA was } \\
\text { not done in this study. }\end{array}$ \\
\hline Amin, 2012 [4] & $\begin{array}{l}\text { Investigate effect of i.v. PACAP38 } \\
\text { infusion on MCA and MMA in } \\
\text { healthy volunteers. }\end{array}$ & $\begin{array}{l}\text { MR-angiography before } \\
\text { and after iv infusion of } \\
\text { PACAP38. }\end{array}$ & $\begin{array}{l}\text { Large dilation of the MMA } \\
\text { but no change of the MCA } \\
\text { caliber. }\end{array}$ & $\begin{array}{l}\text { MMA dilation was } \\
\text { long-lasting (110 min), } \\
\text { while MCA remained } \\
\text { unchanged. }\end{array}$ \\
\hline Amin, 2014 [5] & $\begin{array}{l}\text { Investigate effect of i.v. PACAP38 } \\
\text { infusion on MCA and MMA in } \\
\text { migraine patients. }\end{array}$ & $\begin{array}{l}\text { MR-angiography before and } \\
\text { after iv infusion of PACAP38. }\end{array}$ & $\begin{array}{l}\text { Large dilation of the MMA } \\
\text { but no change of the MCA } \\
\text { caliber. }\end{array}$ & $\begin{array}{l}\text { MMA dilation was } \\
\text { long-lasting (120 min), } \\
\text { while MCA remained } \\
\text { unchanged. } \\
\text { Median time from } \\
\text { infusion start to onset } \\
\text { of migraine was } 4.5 \mathrm{~h} \text {. }\end{array}$ \\
\hline
\end{tabular}

PTS-6 protein transport system-6, BBB blood-brain barrier, PACAP pituitary adenylate cyclase-activating polypeptide, $B S C B$ blood-spinal cord barrier, $M C A$ middle cerebral artery, ICR outbred mouse, SAMP8 a mouse model of Alzheimer, where altered BBB to other substances is known, LPS lipopolysaccharide (used to disrupt the BBB), TAT a peptide derived from the human immunodeficiency virus 1, MMA middle meningeal artery

denying access to PACAP38 from the blood to the smooth muscle cell where the PACAP-receptors are located. PACAP-receptors are found in the entire brain and one study reported uptake of I-PACAP38 in all brain regions after intranasal administration [17]. It would be interesting to directly compare effect on the central nervous system and cerebral arteries after intravenous and intranasal administration.

It has previously been speculated and suggested that the $\mathrm{BBB}$ might be more permeable during migraine attacks [25]. However, recent advanced MRI using intravenous gadolinium contrast performed during and outside of attacks of migraine with [26] and without aura [27] reported no significant change in the BBB permeability. The clinical impact of determining whether intravenous PACAP has a CNS effect is related to the potential of developing PACAP or PACAP receptor antibodies as treatment. Currently, there is an ongoing PAC1 receptor antibody trial for migraine treatment (ClinicalTrials.gov Identifier: NCT03238781).

\section{Conclusion}

PACAP38 transport from the blood to brain and from brain to blood is saturable carrier-mediated, whereas PACAP27 crosses the BBB from the blood to brain by transmembrane diffusion. The transport of PACAP27 the brain to blood is mediated by a saturable and peptidecarrier. There is no solid evidence yet of PACAP38 passing the $\mathrm{BBB}$ following exogenous infusion in migraine models that can lead to brain function and brain vessel changes, so it is possible that the PACAP migraine inducing effect is caused by peripheral mechanisms, which could be via inducing changes in the meninges or affecting nociceptors in extracranial vessels both devoid of the BBB. Future advanced in vivo human studies and exploration of PAC1-receptor antibodies using radio-labelled tracers are highly needed to clarify how and where PACAP may lead to the development of migraine pain.

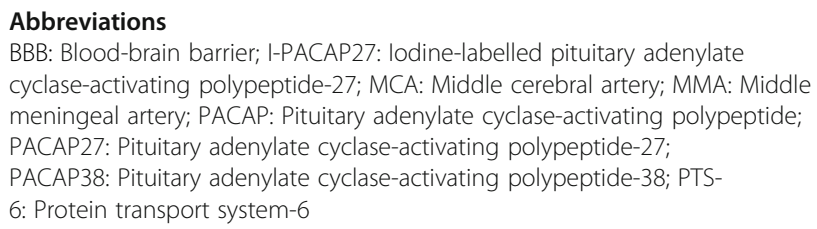
cyclase-activating polypeptide-27; MCA: Middle cerebral artery; MMA: Middle meningeal artery; PACAP: Pituitary adenylate cyclase-activating polypeptide; PACAP27: Pituitary adenylate cyclase-activating polypeptide-27; PACAP38: Pituitary adenylate cyclase-activating polypeptide-38; PTS6: Protein transport system-6

Funding

We thank the Lundbeck Foundation (R155-2014-171) and the Novo Nordisk Foundation (NNF110C1014333).

\section{Availability of data and materials}

All papers included in this review can be found online.

\section{Authors' contributions}

FMA conducted the literature search. FMA and HWS contributed with data interpretation, drafting and revision of the manuscript. Both authors read and approved the final manuscript.

\section{Ethics approval and consent to participate}

Not applicable.

\section{Competing interests}

FMA has received travel grants or speaking fees for speaking for Allergan and Novartis. HWS has received travel grants or speaking fees from Pfizer, Autonomic Technologies and Novartis.

\section{Publisher's Note}

Springer Nature remains neutral with regard to jurisdictional claims in published maps and institutional affiliations.

Received: 12 January 2018 Accepted: 2 May 2018

Published online: 21 May 2018

\section{References}

1. Harmar AJ, Fahrenkrug J, Gozes I, Laburthe M, May V, Pisegna JR, Vaudry D, Vaudry H, Waschek JA, Said SI (2012) Pharmacology and functions of receptors for vasoactive intestinal peptide and pituitary adenylate cyclaseactivating polypeptide: IUPHAR review 1. Br J Pharmacol 166:4-17

2. Schytz HW, Birk S, Wienecke T, Kruuse C, Olesen J, Ashina M (2009) PACAP38 induces migraine-like attacks in patients with migraine without aura. Brain 132:16-25

3. Guo S, Vollesen AL, Hansen RD, Esserlind AL, Amin FM, Christensen AF, Olesen J, Ashina M (2017) Part I: pituitary adenylate cyclase-activating 
polypeptide-38 induced migraine-like attacks in patients with and without familial aggregation of migraine. Cephalalgia 37:125-135

4. Amin FM, Asghar MS, Guo S, Hougaard A, Hansen AE, Schytz HW, van der Geest RJ, de Koning PJH, Larsson HBW, Olesen J, Ashina M (2012) Headache and prolonged dilatation of the middle meningeal artery by PACAP38 in healthy volunteers. Cephalalgia 32:140-149

5. Amin FM, Hougaard A, Schytz HW, Asghar MS, Lundholm E, Parvaiz Al, de Koning PJ, Andersen MR, Larsson HB, Fahrenkrug J, Olesen J, Ashina M (2014) Investigation of the pathophysiological mechanisms of migraine attacks induced by pituitary adenylate cyclase-activating polypeptide-38. Brain 137:779-794

6. Vaudry D, Falluel-Morel A, Bourgault S, Basille M, Burel D, Wurtz O, Fournie A, Chow BK, Hashimoto H, Galas L, Vaudry H (2009) Pituitary adenylate cyclase-activating polypeptide and its receptors: 20 years after the discovery. Pharmacol Rev 61:283-357

7. Dogrukol-Ak D, Tore F, Tuncel N (2004) Passage of VIP/PACAP/secretin family across the blood-brain barrier: therapeutic effects. Curr Pharm Des 10:1325-1340

8. Grände G, Nilsson E, Edvinsson L (2013) Comparison of responses to vasoactive drugs in human and rat cerebral arteries using myograph and pressurized cerebral artery method. Cephalalgia 33:152-159

9. Schytz HW, Olesen J, Ashina M (2010) The PACAP receptor: a novel target for migraine treatment. Neurotherapeutics 7:191-196

10. Banks WA, Kastin AJ, Komaki G, Arimura A (1993) Passage of pituitary adenylate cyclase activating polypeptide1-27 and pituitary adenylate cyclase activating polypeptide1-38 across the blood-brain barrier. J Pharmacol Exp Ther 267:690-696

11. Banks WA, Kastin AJ, Arimura A (1998) Effect of spinal cord injury on the permeability of the blood-brain and blood-spinal cord barriers to the neurotropin PACAP. Exp Neurol 151:116-123

12. Mizushima H, Banks WA, Dohi K, Shioda S, Matsumoto H, Matsumoto K (1999) The effect of cardiac arrest on the permeability of the mouse bloddbrain and blood-spinal cord barrier to pituitary adenylate cyclase activating polypeptide (PACAP). Peptides 20:1337-1340

13. Mizushima H, Banks W, Dohi K, Nakamura Y, Matsumoto K, Shioda S (2000) The effect of cardiac arrest on the permeability of the mouse blood-brain and blood-spinal cord barriers to PACAP. Ann N Y Acad Sci 921:289-292

14. Nonaka N, Banks WA, Mizushima H, Shioda S, Morley JE (2002) Regional differences in PACAP transport across the blood-brain barrier in mice: a possible influence of strain, amyloid beta protein, and age. Peptides 23:2197-2202

15. Nonaka N, Shioda S, Banks WA (2005) Effect of lipopolysaccharide on the transport of pituitary adenylate cyclase activating polypeptide across the blood-brain barrier. Exp Neurol 191:137-144

16. Dogrukol-Ak D, Kumar VB, Ryerse JS, Farr SA, Verma S, Nonaka N, Nakamachi T, Ohtaki H, Niehoff ML, Edwards JC, Shioda S, Morley JE, Banks WA (2009) Isolation of peptide transport system- 6 from brain entothelial cells: therapeutic effects with antisense inhibition in Alzheimer and stroke models. J Cereb Blood Flow Metab 29:411-422

17. Nonaka N, Farr SA, Nakamachi T, Morley JE, Nakamura M, Shioda S, Banks WA (2012) Intranasal administration of PACAP: uptake by brain and regional brain targeting with cyclodextrins. Peptides 36:168-175

18. Yu R, Zeng Z, Guo X, Zhang H, Liu X, Ding Y, Chen J (2012) The TAT peptide endows PACAP with an enhanced ability to traverse bio-barriers. Neurosci Lett 527:1-5

19. Somogyvári-Vigh A, Pan W, Reglödi D, Kastin AJ, Arimura A (2000) Effect of middle cerebral artery occlusion on the passage of pituitary adenylate cyclase activating polypeptide across the blood-brain barrier in the rat. Regul Pept 91:89-95

20. Knutsson $M$, Edvinsson $L$ (2002) Distribution of mRNA for VIP and PACAP receptors in human cerebral arteries and cranial ganglia. Neuroreport 13:507-509

21. Chan KY, Baun M, de Vries R, van den Bogaerdt AJ, Dirven CM, Danser AH, Jansen-Olesen I, Olesen J, Villalón CM, MaassenVanDenBrink A, Gupta S (2011) Pharmacological characterization of VIP and PACAP receptors in the human meningeal and coronary artery. Cephalalgia 31:181-189

22. Guo S, Vollesen AL, Olesen J, Ashina M (2016) Premonitory and nonheadache symptoms induced by CGRP and PACAP38 in patients with migraine. Pain 17:2773-2781

23. Maniyar FH, Sprenger T, Monteith T, Schankin C, Goadsby PJ (2014) Brain activations in the premonitory phase of nitroglycerin-triggered migraine attacks. Brain 137:232-241

24. Amin FM, Hougaard A, Magon S, Asghar MS, Ahmad NN, Rostrup E, Sprenger T, Ashina M (2016) Change in brain network connectivity during
PACAP38-induced migraine attacks: a resting-state functional MRI study. Neurology 86:180-187

25. Ashina M, Tvedskov JF, Lipka K, Bilello J, Penkowa M, Olesen J (2010) Matrix metalloproteinases during and outside of migraine attacks without aura. Cephalalgia 30:303-310

26. Hougaard A, Amin FM, Christensen CE, Younis S, Wolfram F, Cramer SP, Larsson HBW, Ashina M (2017) Increased brainstem perfusion, but no blood-brain barrier disruption, during attacks of migraine with aura. Brain 140:1633-1642

27. Amin FM, Hougaard A, Cramer SP, Christensen CE, Wolfram F, Larsson HBW, Ashina M (2017) Intact blood-brain barrier during spontaneous attacks of migraine without aura: a 3T DCE-MRI study. Eur J Neurol 24:1116-1124

\section{Submit your manuscript to a SpringerOpen ${ }^{\circ}$ journal and benefit from:}

- Convenient online submission

- Rigorous peer review

- Open access: articles freely available online

- High visibility within the field

- Retaining the copyright to your article

Submit your next manuscript at $>$ springeropen.com 